\title{
Uso do Índice de Vegetação por Diferença Normalizada (NDVI) para Análise da Distribuição e Vigor da Vegetação no Pantanal Norte
}

\author{
Use of the Normalized Difference Vegetation Index (NDVI) to Analyze the Distribution \\ and Vigor of Vegetation in the Northern Pantanal
}

\begin{abstract}
Uso del Índice de Vegetación por Diferencia Normalizada (NDVI) para el Análisis de la Distribución y Vigor de Vida en el Pantanal Norte
\end{abstract}

\author{
Gustavo Benedito Medeiros Alves ${ }^{1}$ \\ Simoni Maria Loverde-Oliveira ${ }^{2}$
}

\begin{abstract}
RESUMO: Considerando a complexidade de macrohabitats no Pantanal e suas relações com as variações hidrológicas, o objetivo deste estudo foi comparar a variação fitofisionômica e o comportamento temporal do Índice de Vegetação por Diferença Normalizada (NDVI) considerando o

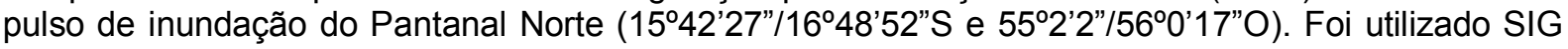
Arcgis 10.2.2. e imagens MODIS (MOD13Q) para mapeamento da variação da massa foliar (2010 a 2012). Para a área total $(7.553,28$ quilômetros quadrados) houve aumento do dobro de vegetação de alto vigor do período seco para o chuvoso. Os maiores valores na enchente e águas altas corroboram com a afirmação de que a inundação se correlaciona com o acréscimo do vigor de vegetação, que se torna mais densa na Savana Florestada (43\%) e Floresta Estacional Semidecidual Aluvial (35\%) e menor na Savana Gramíneo - Lenhosa e Parque (22\%). Durante as águas baixas a vegetação diminui sua massa foliar e as classes Savana Gramínea - Lenhosa e Savana Parque ocupam ampla área da planície (81\%), em compensação a Savana Florestada (13\%) e Floresta Estacional Semidecidual Aluvial $(6 \%)$ sofreram redução em sua cobertura foliar. O NDVI foi eficiente para a interpretação da variação foliar, numa região onde a dinâmica de inundação cria paisagens vegetacionais diversificadas.
\end{abstract}

PALAVRAS-CHAVE: Imagens orbitais. Geotecnologias. Áreas úmidas.

ABSTRACT: Considering the complexity of macrohabitats in the Pantanal and their relationship with hydrological variations, the study aimed to compare the phytophysiognomy variation and the temporal behavior of the Normalized Difference Vegetation Index (NDVI) considering the flood pulse of the

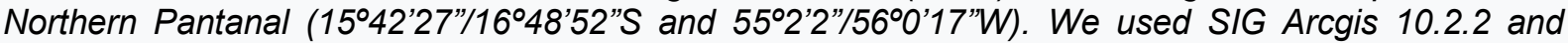
MODIS images (MOD13Q) for mapping of leaf mass variation (2010 to 2012). For the total area (7,553.28 square kilometers) there was an increase of twice the high vigor vegetation from the dry to the rainy season. The highest values recorded for NDVI in flood and high waters corroborate the statement that the flood correlates with the increase in vegetation vigor, which becomes denser in the Forested Savannah (43\%) and the Semideciduous Seasonal Alluvial Forest (35\%) and smaller in the

\footnotetext{
${ }^{1}$ Universidade Federal de Mato Grosso, Avenida dos Estudantes, 5055. Rondonópolis, Mato Grosso. 78736-900. gustavo.benedito@hotmail.com.

2 Universidade Federal de Mato Grosso, Avenida dos Estudantes, 5055. Rondonópolis, Mato Grosso. 78736-900. si.loverde@hotmail.com.
} 
Grassy-Woody Savannah and Park (22\%). In the low waters, the vegetation decreases its leaf mass and the Grassy-Woody Savannah and Park Savannah classes occupy a wide area of the plain (81\%), in contrast to Forested Savannah (13\%) and Semideciduous Seasonal Alluvial Forest (7\%) show a reduction in leaf cover. The NDVI were efficient in the analysis and interpretation of leaf variation in a region where the flood creates diversified vegetation landscapes.

KEYWORDS: Orbital images. Geotechnologies. Wetland.

RESUMEN: Considerando la complejidad de los macrohabitats en el Pantanal y su relación con las variaciones hidrológicas, el objetivo del estudio fue comparar la variación fitofisonómica y el comportamiento estacional del Índice de Vegetación por Diferencia Normalizada (NDVI) considerando

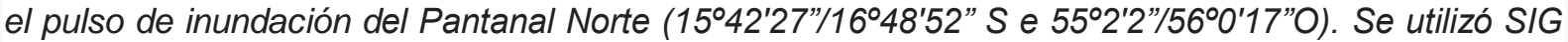
Arcgis 10.2.2. e imágenes MODIS (MOD13Q) para mapear la variación de masa foliar (2010 a 2012). Sobre un área total de 7.553,28 kilómetros cuadrados el incremento fue del doble de la vegetación de alto vigor durante el período seco a lluvioso. Los mayores valores para NDVI en la crecida y aguas altas corroboran con la afirmación de que la inundación se correlaciona con el crecimiento del vigor de vegetación, que se torna más densa en la Sabana Floresta (43\%) y Floresta Estacional Semidecidual Aluvial (35\%) y menor en la Sabana Gramíneo-Leñosa y Parque (22\%). Contrariamente aguas abajo la vegetación disminuye su masa foliar y las clases Sabana Gramínea-Leñosa y Sabana Parque ocupan un área de la planicie (81\%), en compensación a la Sabana Floresta (13\%) y Floresta Estacional Semidecidual Aluvial (6\%) que sufrió una reducción en su cobertura foliar. Los datos de NDVI se muestran eficientes en el análisis e interpretación de variación foliar de la vegetación, en una región donde la dinámica de inundación crea paisajes vegetales diversificados.

PALABRAS-CLAVE: Imágenes orbitales. Geotecnologías. Humedal.

\section{INTRODUÇÃO}

As áreas úmidas são um dos três maiores ecossistemas do mundo (AUSSEIL; DYMOND; SHEPHERD, 2007) e no Brasil cobre cerca de $20 \%$ do território com tamanhos e formas muito diversas (CUNHA; PIEDADE; JUNK, 2015). Estas terras são muito valiosas em termos de diversidade, produtividade biológica e serviços ecossistêmicos (CASTAÑEDA et al., 2015; COSTANZA et al., 2014). A distribuição das espécies e a diversidade variam dentro e entre os diferentes hábitats dispostos ao longo do gradiente de inundação, desde os não inundáveis até os sazonais e os permanentemente inundados (JUNK; SILVA; CUNHA, 2011; SILVA et al., 2001).

O entendimento da variabilidade hidrológica como macrofator direcionador dos processos ambientais, sociais e econômicos em planícies de inundação pode ser usado pela sociedade para se precaver uma vez que alterações drásticas nas máximas e mínimas inundações influência nas práticas de exploração econômica da região (KMITTA, 2010; PADOVANI et al., 2011; SILVA, 2013) e tem relação direta com a manutenção dos processos e distribuição das comunidades vegetais. Além das variações hidrológicas, Cunha, Piedade e Junk (2015) apontam que o impacto do fogo e as diferentes atividades 
humanas resultam em grande dinâmica no desenvolvimento da vegetação. Para estes autores, devemos considerar a relevância da dinâmica hidrológica, dos parâmetros físicos e químicos do solo e da água e a composição e estrutura botânica das áreas úmidas brasileiras, visando facilitar o manejo sustentável dos macrohabitats e pautar as discussões políticas a respeito da exploração e da proteção destes locais, alguns amplamente explorado por distintos usos.

Apesar da importância, o processo de inundação e suas implicações ainda não é bem compreendido, isso se deve, principalmente, à falta do emprego de métodos de análise e tecnologias que permitam caracterizar e monitorar de forma contínua esse ambiente, além de permitir que se façam cenários e previsões do comportamento do sistema como um todo (PADOVANI, 2010). Uma das possibilidades apresentadas atualmente para conhecer e quantificar as áreas submetidas a inundações sazonais é o uso de geoprocessamento e imagens orbitais de satélite, combinados a índices como o Índice de Vegetação por Diferença Normalizada (NDVI), uma vez que é adequado a áreas extensas e de difícil acesso, como no caso do Pantanal (MIURA et al., 2001).

O NDVI é um índice que permite monitorar, em grande escala, o vigor da vegetação, em épocas de menor ou maior cobertura da vegetação (PORTZ; GUASSELLI; CORRÊA, 2011). No caso do Pantanal, desempenha um papel importante no monitoramento da resposta da vegetação nas épocas de seca e de enchentes (CACCAMO et al., 2011; GU et al., 2008). Assim, esse índice é útil para a identificação e monitoramento de grandes áreas com estresse vegetacional resultado da seca ou da supersaturação do solo após enchentes e chuvas excessivas (PENATTI, 2014), permitindo estudar mudanças sazonais e interanuais de vegetação (VIANA; ALVALÁ, 2010) e quantificar a disponibilidade de pastagem para o rebanho nas diferentes fases hidrológicas.

Neste contexto, este estudo teve como propósito comparar a variação fitofisionômica e o comportamento temporal do NDVI, considerando o pulso de inundação do Pantanal Norte, entre os anos de 2010 a 2012.

\section{MATERIAL E MÉTODOS}

\section{Área de Estudo}

O estudo foi realizado na bacia hidrográfica do Alto Rio Paraguai na planície de inundação do Pantanal Norte, no estado de Mato Grosso. Foi delimitado um quadrante (753.328 hectares), como área de estudo (Figura 1), abrangendo fragmentos dos pantanais de São Lourenço Norte, São Lourenço-Sul, Piquiri-Itiquira, Bento Gomes e Chacororé, conforme as sub-regiões pantaneiras estabelecidas por Padovani (2010). Esta delimitação 
em quadrante teve como objetivo facilitar a análise do fluxo das águas desse território, que se comporta como sistema aberto recebendo contribuição dos diferentes agentes hídricos da rede de drenagem do planalto e da planície, além das precipitações locais.

Figura 1 - Localização do quadrante de estudo com os principais cursos d'água, em destaque as regiões pantaneiras, de acordo com Padovani (2010)

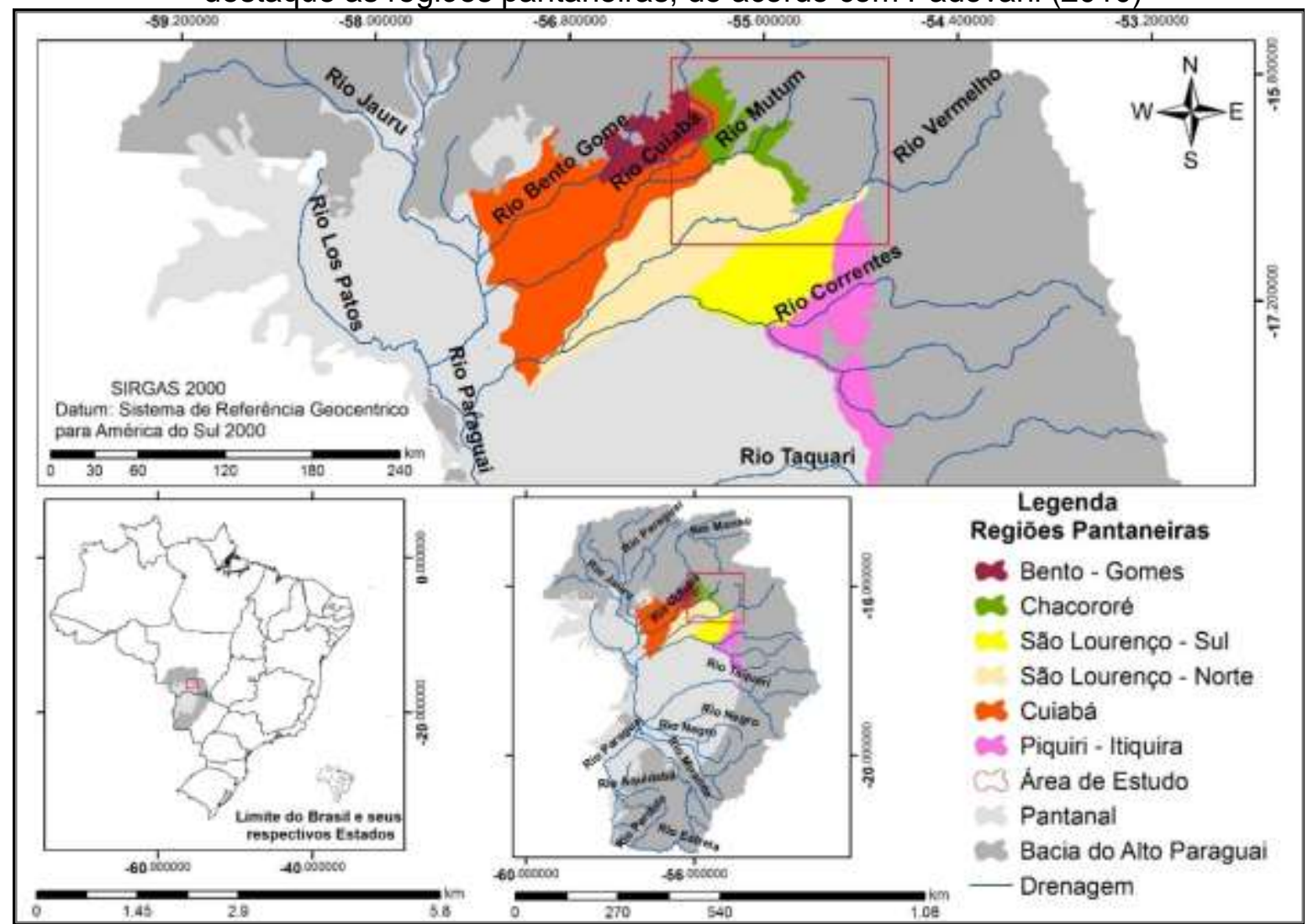

Fonte: Alves (2015).

O clima da região é o tropical úmido, com invernos secos (estação seca) e verões chuvosos (estação úmida). A temperatura média é de 24 a $26^{\circ} \mathrm{C}$, com precipitação anual variando de 1000-1600 milímetros (ALVARES et al., 2014). As maiores médias mensais de precipitação da região ocorrem em janeiro, fevereiro e março, e o período com menor precipitação ocorre nos meses de junho e agosto. A variação média da vazão dos rios Vermelho/São Lourenço e Cuiabá, que drenam a área de estudo, acompanha a mesma tendência das precipitações (ALVES, 2015).

O Pantanal Norte compreende a microrregião do Alto Pantanal (em Mato Grosso) cuja topografia é formada por diferentes cotas de elevação da bacia hidrográfica formando o planalto e a planície. Segundo Alves (2015) no planalto as altitudes variam entre 250 e 860 metros, onde localiza-se as cabeceiras dos rios da bacia do Alto Paraguai (BAP), entre eles os principais cursos d'água que abastecem a região do quadrante - rios Vermelho/São Lourenço, Cuiabá e Mutum (Figura 1). Sabe-se que no período de inundação estes rios, 
conforme relatado por Cunha, Piedade e Junk (2015), promovem o alagamento de grandes áreas ao longo dos sistemas de drenagem na porção de planície da Bacia do Alto rio Paraguai, criando, na extensão dos seus cursos, áreas de vegetação ripária, cobertas tanto com vegetação florestal como herbáceo/arbustiva.

O uso e ocupação da terra no território aqui considerado é composto basicamente por formações de Cerrado, agricultura e pastagens em sua maioria, e por matas no entorno dos corpos d'água permanentes. A vegetação nesse território apresenta diferentes classes, conforme descrevem Alves, Loverde-Oliveira e Oliveira (2015), destacando-se o Ecótono Savana, Floresta Estacional Decidual, Floresta Estacional Semidecidual, Formações Pioneiras, Savana (cerrado), Savana Estépica (chaco) e áreas desmatadas (uso para a pecuária e agricultura) (Figura 2).

Figura 2 - Mapa de localização do quadrante de estudo e das classes de uso e cobertura da terra da bacia do Alto Paraguai

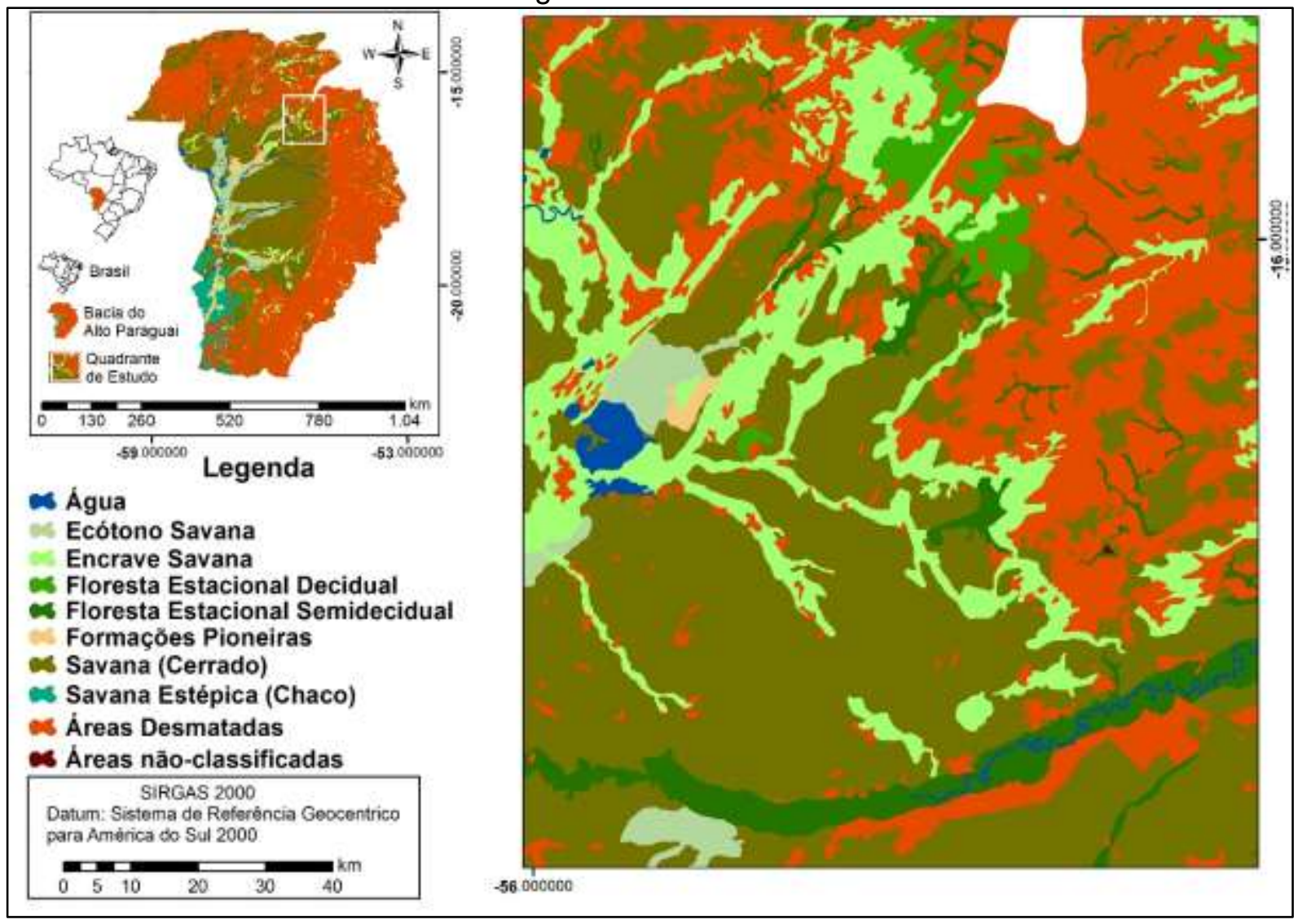

Fonte: Alves (2015).

\section{PROCEDIMENTOS METODOLÓGICOS}

A análise da variação fitofisionômica e o comportamento temporal do Índice de Vegetação por Diferença Normalizada foram realizados levando em consideração a dinâmica de entrada e saída da água no território do quadrante, de acordo com a 
metodologia descrita em Alves et al. (2019). Assim, com o propósito interpretar e detectar a distribuição e o vigor da vegetação nas distintas fases do pulso de inundação do Pantanal (águas altas e águas baixas), aplicou-se o NDVI, seguindo a metodologia proposta por Padovani (2010) e Silveira (2015). Tomando como base os resultados de Alves (2015) foram definidos o período com maior (2010 - 2011) e menor (2011 - 2012) nível de inundação do quadrante de estudo e as cotas de elevação dos locais que sofrem inundações, ou seja, áreas inferiores a 206 metros.

Para estabelecimento do NDVI foram adquiridas no banco de dados da NASA imagens MODIS 13Q1, composição de 16 dias com resolução espacial de 250 metros para os dias: 13/08/2010, 02/12/2010, 21/03/2011 (maiores inundações), 13/08/2011, 02/12/2011, 05/03/2012 (menores inundações). O processamento das imagens foi realizado no ArcMap 10.2, e o NDVI calculado utilizando as bandas do infravermelho próximo (IV) e do vermelho (V) na seguinte fórmula: $\mathrm{NDVI}=(\mathrm{IV}-\mathrm{V}) /(\mathrm{IV}+\mathrm{V})$. O NDVI varia de -1 a 1 e está diretamente relacionado com o vigor da vegetação, valores mais altos indicam vegetação mais vigorosa. Os valores do índice foram divididos em quatro classes, sendo; -1 a 0 classificado como água; 0 a 0,4 como baixo vigor; 0,4 a 0,7 médio vigor; e 0,7 a 1 alto vigor.

Salienta-se que estes valores foram determinados através das classificações supervisionadas das imagens de satélites e dos dados coletados em situ, conforme a metodologia de MacAlister e Mahaxay (2009). Segundo esses autores a classificação supervisionada usa dados de treinamento - áreas de pixels com tipo de classe conhecida (análise a campo) para treinar o computador a reconhecer as variações espectrais e consequentemente a conversão dos dados em classes de vigor de vegetação. Com base nos dados da pesquisa de campo, as áreas de treinamento foram selecionadas para suportar o algoritmo de classificação supervisionada usando a regra Classificação de Máxima Verossimilhança (MLC). Segundo Schowengerdt (2006), essa técnica tem como objetivo identificar os tipos de cobertura e uso do solo ao nível de pixel a partir dos padrões de resposta espectral do solo, água, área urbana e floresta, entre outros objetos que podem ser identificados nas imagens de sensores remotos orbitais.

Os resultados foram associados a quatro classes, conforme o Manual Técnico da Vegetação Brasileira do IBGE (2012), sendo então classificados como Corpo d'água Continental, Savana Gramíneo - Lenhosa e Savana Parque, Savana Florestada e Floresta Estacional Semidecidual Aluvial.

Para testar a confiabilidade dos resultados do NDVI foram realizadas coletas de campo (entre janeiro e outubro/2015), com o objetivo de registrar os diferentes extratos vegetacionais e analisar as fases do ciclo hidrológico da região em diferentes unidades de paisagem (Figura 3). 
Figura 3 - Vista geral do campo inundável do Pantanal, vegetação florestal ou savânica, nas diferentes fases do pulso de inundação
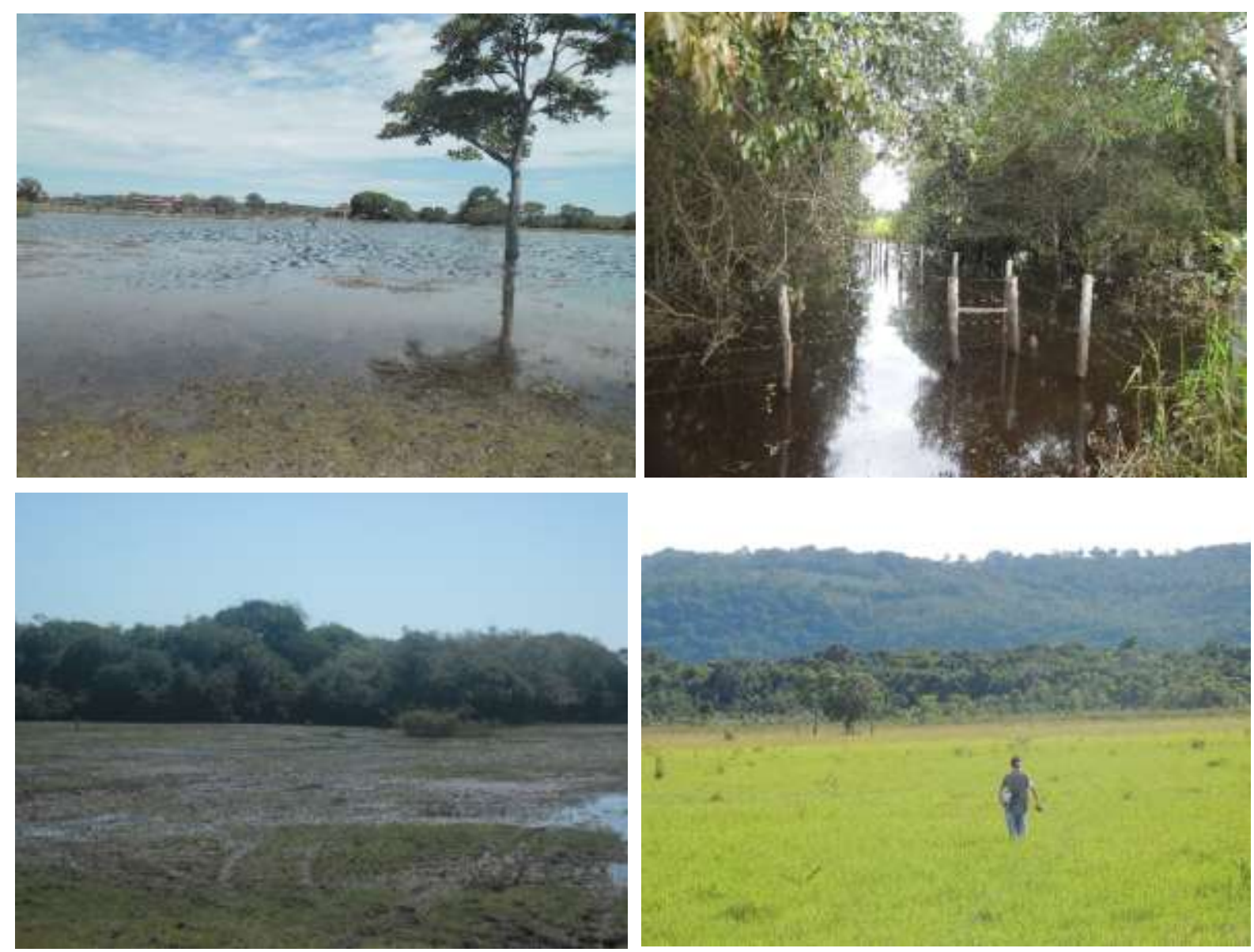

Fonte: os próprios autores.

\section{RESULTADOS E DISCUSSÃO}

Neste estudo, buscou-se comparar a variação fitofisionômica e o comportamento temporal do NDVI considerando o pulso de inundação do Pantanal Norte. Encontrou-se que a cobertura vegetal (NDVI) na área de interesse teve forte relação com a sazonalidade das precipitações locais e regionais e com a variabilidade do pulso de águas baixas e altas.

Considerando o vigor da vegetação destaca-se que houve variação de -1 a 1 diretamente relacionados com os valores do NDVI. Os resultados do índice foram associados as classes de vegetação, sendo; -1 a 0,25 classificados como Corpo d'água Continental; 0,25 a 0,56 - Savana Gramíneo - Lenhosa e Savana Parque; 0,56 a 0,76 Savana Florestada; 0,76 a 1 - Floresta Estacional Semidecidual Aluvial.

As épocas com maior disponibilidade hídrica foram caracterizadas pelo maior vigor das formações florestais e demonstraram um padrão inverso nas águas baixas tanto no vigor da vegetação quanto nas classes de vegetação, com menor predominância das 
classes florestadas. Essa informação corrobora com outros estudos realizados em planícies de inundação (GOLTZ et al., 2007; MACHADO et al., 2014; MIOTO; PARANHOS FILHO; ALBREZ, 2012).

Os valores do NDVI na época de inundação e águas altas foram superiores aos valores de águas baixas, comprovando que nas épocas com maior disponibilidade hídrica a vegetação é mais densa e bem desenvolvida na Savana Florestada e Floresta Estacional Semidecidual. Diferentemente nas águas baixa quando a vegetação diminui sua massa foliar e a classe de vegetação Savana Gramínea - Lenhosa e Savana Parque ocupa ampla área da planície (Figura 4, 5 e Tabela 1). Nas águas baixas a classe de vegetação com maior predominância foi a Savana Gramíneo - Lenhosa e Savana Parque, sendo que nos anos de 2010 e 2011 ocupou uma área de até 81\%; e a Savana Florestada correspondeu a $13 \%$ da massa foliar do território de estudo. A menor classe de vegetação para esse período foi representada pela Floresta Estacional Semidecidual cobrindo 4\% e $6 \%$, respectivamente (Figuras 4 e 5 e Tabela 1).

Nas águas baixas o decréscimo da área coberta pela vegetação com maior vigor esteve relacionado com a reduzida disponibilidade hídrica que ficou restrita a corpos d'água permanentes. Esse comportamento de declínio da área coberta pela Floresta e sua manutenção mais restrita a cursos d'água é compatível com estudos utilizando o NDVI (ESQUERDO; ANTUNES, 2010) na planície pantaneira, no qual foi constado que a vegetação marginal se manteve constante ao longo dos meses, porém com queda a partir de junho quando as árvores começam a perder suas folhas havendo redução nos valores de NDVI.

A partir de dezembro de 2010 , com as chuvas mais intensas, as áreas que não são drenadas pelos rios passaram a ter maior suprimento de água no solo e a vegetação tendeu a ganhar maior volume de massa foliar (Figuras 4 e 5 e Tabela 1). Nesta época a Savana Florestada passa a se destacar cobrindo até 34\% da área (2010-2011 e 2011 - 2012); a Floresta Estacional Semidecidual representou 37\% (2010-2011) e 26\% (2011-2012) do território de estudo; e a Savana Gramíneo - Lenhosa e Savana Parque representou 28\% (2010-2011) e 39\% (2011- 2012). Wang, Rich e Price (2003) e Ferrari, Silva e Abdon (2009) afirmam que a quantidade de biomassa vegetacional está relacionado com o volume de precipitações, ou seja, os valores de NDVI são maiores na época das chuvas. 
Figura 4 - A - NDVI para o período de estiagem (agosto), B - NDVI para o período de enchente, C - NDVI para o período de águas altas (março), entre 2010 e 2011

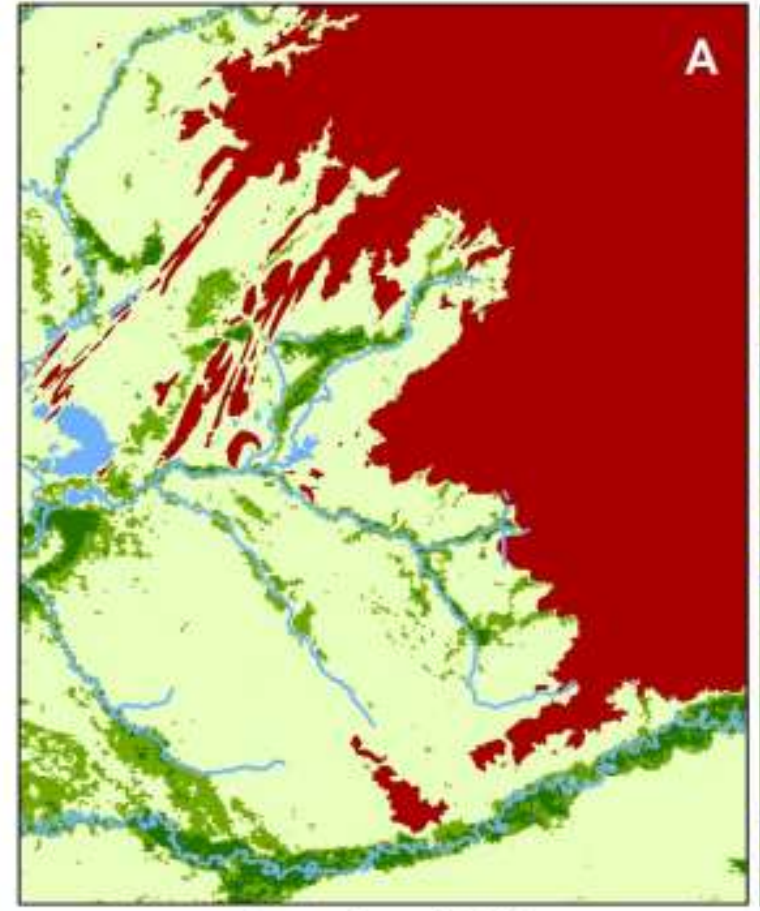

Agosto - 2010

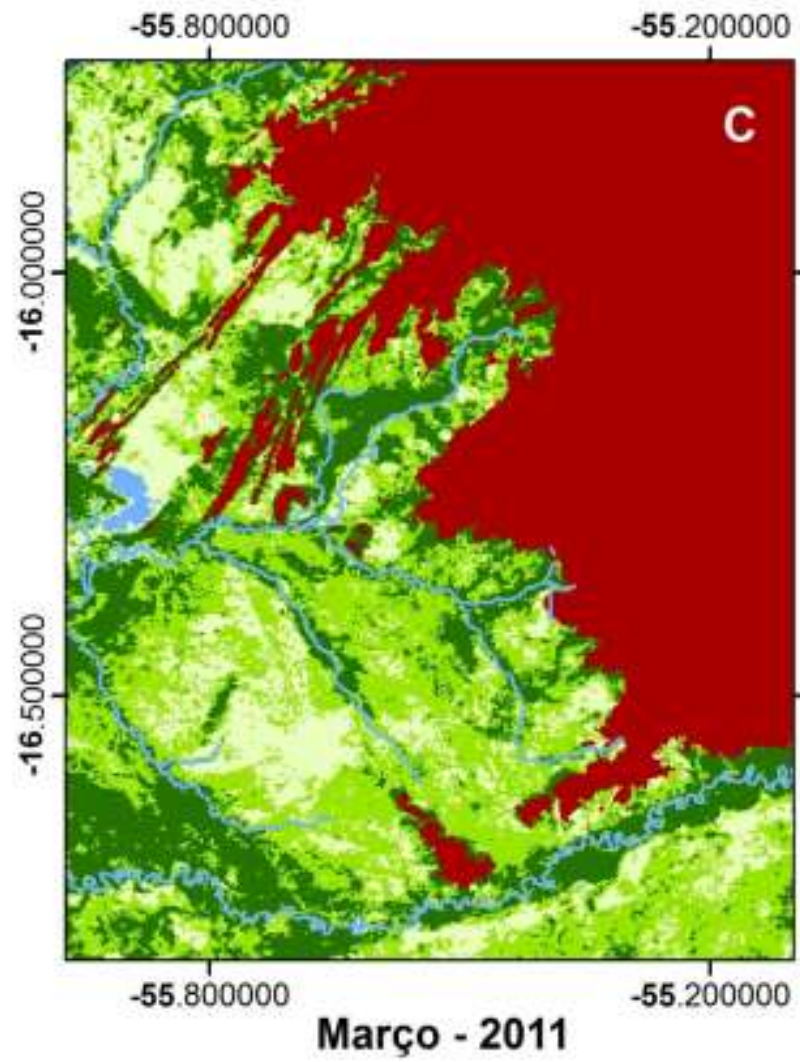

Fonte: Alves (2015).

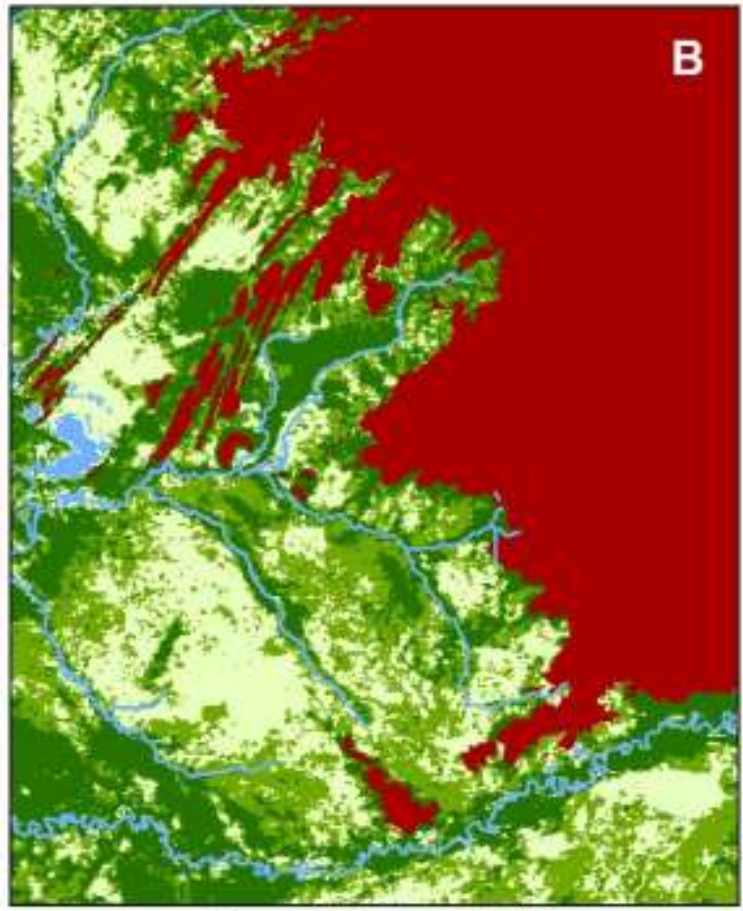

Dezembro - 2010

\section{Legenda}

\section{Corpo d' Água Costeiro}

83 Savana Gramineo - Lenhosa e Savana Parque

Savana Florestada

Floresta Estacional Semidecidual Aluvial

\section{Elevação < 206 metros}

Escala

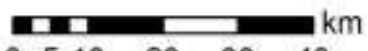

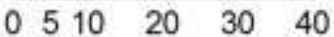
$\left.w\right|_{s} ^{N} E$

常

\begin{tabular}{|c|}
\multicolumn{1}{|c}{ Gráfica } \\
\hline \multicolumn{1}{|c|}{ Projeção } \\
Universal Transversal de Mercador \\
Zona 21 K \\
Datum: SIRGAS 2000
\end{tabular}


Figura 5 - A - NDVI para o período de estiagem, B - NDVI para o período de enchente, C - NDVI para o período de águas altas, entre 2011 e 2012

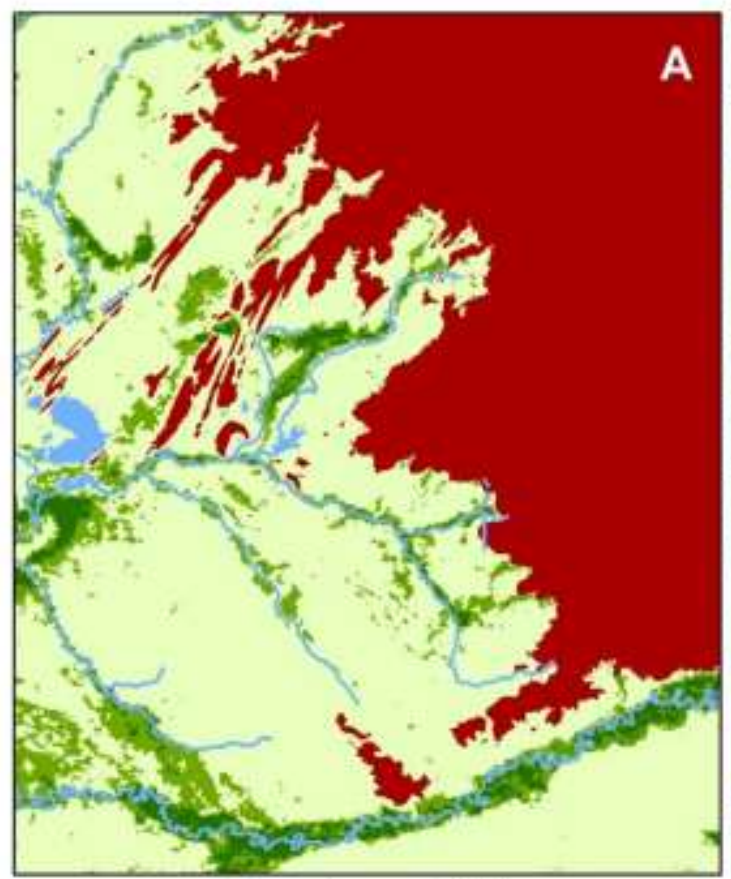

Agosto - 2011

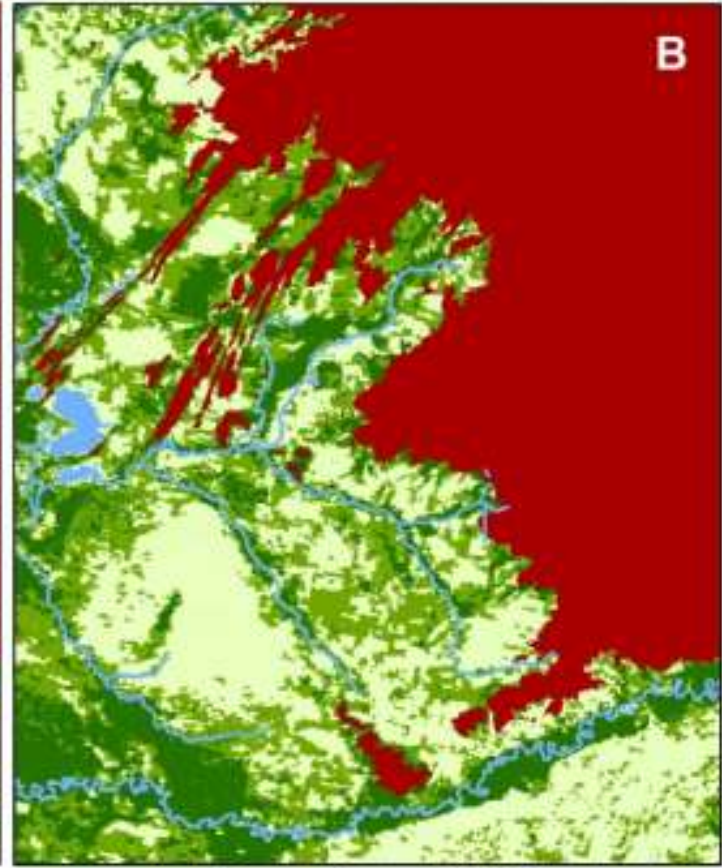

Dezembro - 2011

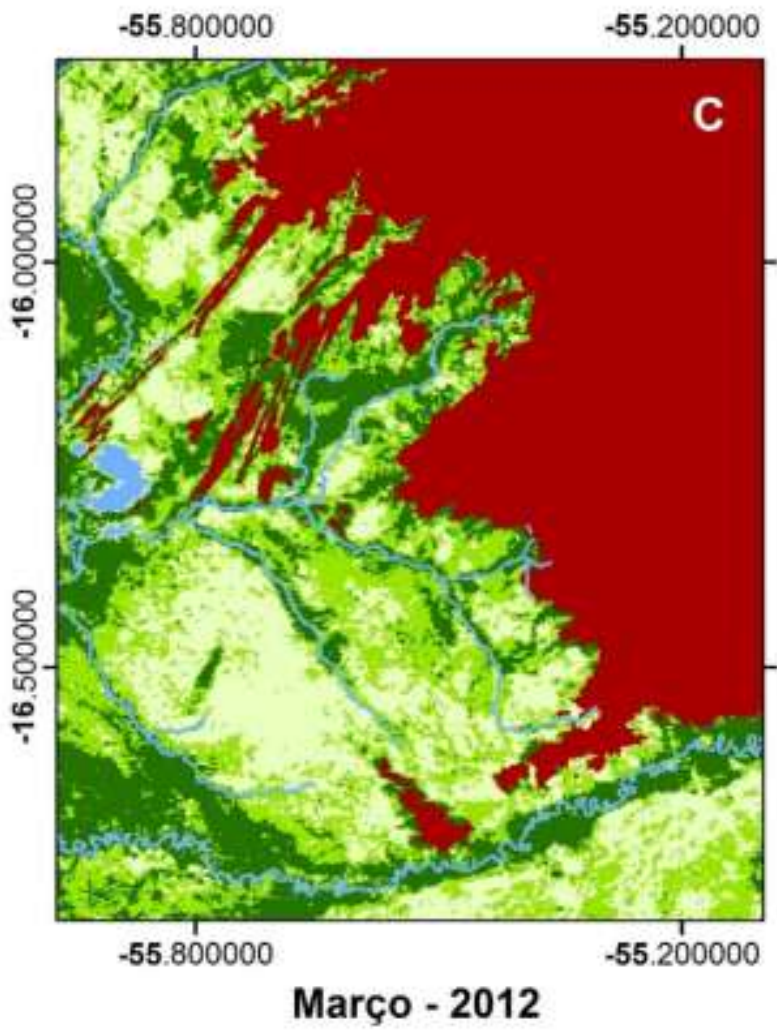

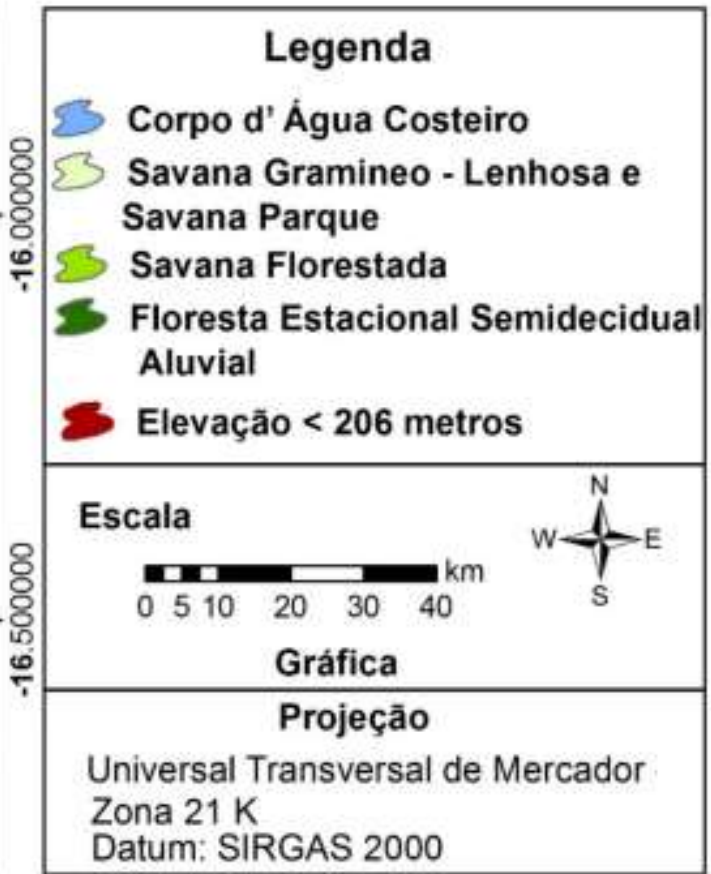

Fonte: Alves (2015).

Os campos de pastagens nativas embora permaneçam parcialmente alagados durante a inundação isto não impede que o gado pastoreie. Já para se proteger e dormir o 
rebanho tende a se deslocar para as áreas mais elevadas das propriedades (cordilheiras e capões) (ALVES, 2015). Os resultados do NDVI mostraram que na planície durante a fase com maior inundação, especialmente em 2011 (ano com pico de inundação), os locais destinados à pastagem (Savana Gramíneo - Lenhosa e Parque) ficaram restritos e representaram somente $30 \%$ na área. Está condição pode acarretar perdas econômicas e necessidade de manejo mais intensivo do gado.

Tabela 1 - Valores das áreas correspondentes aos NDVI por classe de vegetação e outros, nos anos de maior (2010-2011) e menor inundação (2011-2012)

\begin{tabular}{llllllll}
\hline \multicolumn{1}{c}{ NDVI (2010-2011) } & Agosto & (\%) & Dezembro & (\%) & Março & (\%) \\
\hline Corpo d'Água Continental & 9.024 & 1 & 6.405 & 1 & 8.400 & 1 \\
Savana Gramíneo - Lenhosa e Parque & 611.073 & 81 & 212.374 & 28 & 161.908 & 21 \\
Savana Florestada & 99.348 & 13 & 255.702 & 34 & 320.154 & 42 \\
Floresta Estacional Semidecidual Aluvial & 33.883 & 4 & 278.847 & 37 & 262.866 & 35 \\
\hline \multicolumn{1}{c}{ Área Total } & $\mathbf{7 5 3 . 3 2 8}$ & $\mathbf{1 0 0}$ & & & & \\
\hline NDVI (2011-2012) & Agosto & $\mathbf{( \% )}$ & Dezembro & (\%) & Março & (\%) \\
Corpo d'Água Continental & 7.376 & 1 & 6.033 & 1 & 5.432 & 1 \\
Savana Gramíneo - Lenhosa e Parque & 608.133 & 81 & 291.161 & 39 & 222.276 & 30 \\
Savana Florestada & 95.542 & 13 & 252.486 & 34 & 271.327 & 36 \\
Floresta Estacional Semidecidual Aluvial & 42.277 & 6 & 203.648 & 27 & 254.293 & 34 \\
\hline \multicolumn{1}{c}{ Área Total } & $\mathbf{7 5 3 . 3 2 8}$ & $\mathbf{1 0 0}$ & & & & \\
\hline Fonte:Alves (2015). & & & & & &
\end{tabular}

Fonte: Alves (2015).

A redução das chuvas na região coincide com uma planície ainda se mantendo inundada. Nesta condição os valores de NDVI seguem a mesma lógica do período de enchente, ou seja, a vegetação com maior vigor é a Savana Florestada 42\% (2010-2011), 36\% (2011-2012) e Floresta Estacional Semicidual Aluvial 35\% (2010-2011), 33\% (20112012); e a Savana Gramíneo - Lenhosa e Parque conceberam 21\% (2010-2011), 30 \% (2011-2012) (Figuras 4 e 5). A saída das águas do campo e a quase ausência de precipitação leva a vegetação a ficar com reduzida biomassa verde. Além disso, o solo começa a ficar mais exposto dificultando assim a disponibilidade e a qualidade nutricional da alimentação dos bovinos. Os índices calculados neste estudo demostraram que neste período há maior disponibilidade de áreas com potencial para o pastoril chegando a $81 \%$ da área de planície.

Sabe-se que o manejo do gado não é bem compreendido, especialmente porque o ciclo de inundação não é homogêneo no tempo e nos espaços desse território. Assim, Abreu et al. (2008) relatam que é crescente as pesquisas com propósito de aumentar a produtividade da pecuária na região pantaneira. Esta afirmação é um reforço na aplicação de diferentes tecnologias e usos de índices como o NDVI para analisar a dinâmica de 
inundação, mas visando especialmente subsidiar o manejo da pecuária, tão importante economicamente nesta área úmida.

Moraes, Pereira e Arai (2009) observaram que as áreas inundadas apresentam uma maior variação da vegetação, visto que, a cobertura vegetal é alterada pelo nível da água, no entanto nos meses secos há uma redução do vigor vegetativo em todo o Pantanal devido ao déficit hídrico. Outros estudos têm demonstrado que há uma defasagem de dois a três meses na resposta do NDVI e a precipitação (IMMERZEEL; QUIROZ; JONG, 2005; QUIROZ et al., 2011).

Para Ferreira e Huete (2004) a diferença sazonal no NDVI é indicativa de alta atividade fotossintética e acumulação de biomassa no período de chuvas e com baixa biomassa verde no período de estiagem. Viana e Alvalá (2010), avaliando os desempenhos de índices de vegetação (NDVI, EVI e LSWI), constaram que o NDVI apresenta baixa amplitude na estação chuvosa, revelando baixo poder de discriminação da vegetação nesta estação.

$\mathrm{Na}$ região plana da bacia do rio Mutum, pertencente ao território desse estudo, foi detectado por Alves (2015) e Alves, Loverde-Oliveira e Oliveira (2015) que o acréscimo do vigor de vegetação correlaciona-se com alta oferta hídrica proporcionada pela inundação e precipitações enquanto que nas regiões de planalto o NDVI não demonstrou boa aplicação visto que não se trata de uma área submetida a inundações e a disponibilidade de água esteve relacionada com as chuvas locais.

\section{CONSIDERAÇÕES FINAIS}

Os dados do NDVI se mostraram eficientes na análise e interpretação da variação foliar da vegetação numa região onde a dinâmica de inundação cria paisagens vegetacionais diversificadas e estreitamente relacionadas aos períodos de águas altas e baixas. Os resultados obtidos no estudo confirmam o potencial das geotecnologias como ferramenta para o auxílio no armazenamento, análise e mapeamento da dinâmica da massa foliar nos diferentes períodos hidrológicos dessa área úmida. De modo geral, as informações obtidas além de contribuírem para o conhecimento das respostas da vegetação aos processos de inundação sazonal são pertinentes para a comunidade local, pois esse movimento das águas nas regiões pantaneiras obriga os moradores a se adaptarem as diversidades surgidas pelo pulso de inundação, visto que grande parte da economia dessa região é sustentada pela exploração da paisagem local.

Além disso, para outros tomadores de decisões, possibilita o reconhecimento das áreas que estão sujeitas a variação da vegetação e essa compreensão pode facilitar a 
realização do ordenamento do território, conforme a necessidade de conservação ambiental e as finalidades sociais e econômicas.

\section{REFERÊNCIAS}

ABREU, U. G. P.; GOMES, E. G.; LOPES, P. S.; TORRES, R. A.; SANTOS, H. N. Avaliação sistêmica da introdução de tecnologias na pecuária de gado de corte do Pantanal por meio de modelos de análise envoltória de dados (DEA). Revista Brasileira de Zootecnia, Viçosa, v. 37, n. 11, p. 2069-2076, 2008. Disponível em: https://ainfo.cnptia.embrapa.br/digital/bitstream/item/25295/1/Avaliacaosistemicadaintroduca odetecnologias.pdf. Acesso em: 21 out. 2019.

ALVARES, C. A.; STAPE, J. L.; SENTELHAS, P. C.; GONÇALVES, J. L. M.; SPAROVEK, G. Köppen's climate classification map for Brazil. Meteorologische Zeitschrift, Stuttgart, v. 22, n. 6, p. 711-728, 2014. Disponível em:

https://www.schweizerbart.de/papers/metz/detail/22/82078/Koppen_s_climate_classification_ map_for_Brazil?af=crossref. Acesso em: 14 out. 2019.

ALVES, G. B. M. Efeitos da inundação sobre o manejo da pecuária no Pantanal Norte com emprego de imagens orbitais. 2015. Dissertação (Mestrado em Geografia) Universidade Federal de Mato Grosso, Rondonópolis, 2015.

ALVES, G. B. M.; LOVERDE-OLIVEIRA, S. M.; OLIVEIRA, R. L. Uso combinado dos índices LSWI e NDVI para análise da inundação na Bacia do rio Mutum (Pantanal Norte). In: SIMPÓSIO BRASILEIRO DE RECURSOS HÍDRICOS, 21., 2015, Brasília. Anais [...]. Porto Alegre: Sociedade Brasileira de Recursos Hídricos, 2015. p. 1-7.

ALVES, G. B. M.; SANTOS, J. W. M. C.; TONDATO, K. K.; ANGEOLETTO, F.; LOVERDEOLIVEIRA, S. M. Mapeamento da inundação por LSWI e caracterização dos fluxos d'água na bacia do Alto Paraguai, Pantanal Norte, Brasil. Revista Geográfica Venezolana, Los Andes, v. 60, n. 1, p. 92-105, 2019. Disponível em:

http://www.saber.ula.ve/bitstream/handle/123456789/46062/articulo6.pdf?sequence=1\&isAllo wed=y. Acesso em: 14 out. 2019.

AUSSEIL, A. G.; DYMOND, J. R.; SHEPHERD, J. D. Rapid mapping and prioritisation of wetland sites in the Manawatu-Wanganui region, New Zealand. Environmental

Management, New York, v. 39, n. 3, p. 316-325, 2007. Disponível em:

https://www.researchgate.net/publication/6539651_Rapid_Mapping_and_Prioritisation_of_W etland_Sites_in_the_Manawatu-Wanganui_Region_New_Zealand. Acesso em: 14 out. 2019.

CACCAMO, G.; CHISHOM, L. A.; BRADSTOCK, R. A.; PUOTINEN, M. L. Assessing the sensitivity of MODIS to monitor drought in high biomass ecosystems. Remote Sensing of Environment, New York, v. 115, n. 10, p. 2626-2639, 2011. Disponível em: https://www.sciencedirect.com/science/article/abs/pii/S003442571100201X. Acesso em: 14 out. 2019.

CASTAÑEDA, C.; JAVIER GRACIA, F.; LUNA, E.; RODRÍGUEZ-OCHOA, R. Edaphic and geomorphic evidences of water level fluctuations in Gallocanta Lake, NE Spain. Geoderma, Amsterdam, v. 1, p. 265-279, 2015. Disponível em:

https://www.researchgate.net/publication/268446104_Edaphic_and_geomorphic_evidences_ of_water_level_fluctuations_in_Gallocanta_Lake_NE_Spain. Acesso em: 14 out. 2019.

COSTANZA, R.; GROOT, R.; SUTTON, P.; PLOEG, S.; ANDERSON, S. J.; KUBISZEWSKI, I.; FARBER, S.; TURNER, R. K. Changes in the global value of ecosystem services. Global Environmental Change, Amsterdam, v. 26, p. 152-158, 2014. Disponível em: https://www.sciencedirect.com/science/article/abs/pii/S0959378014000685?via\%3Dihub. Acesso em: 14 out. 2019. 
CUNHA, C. N.; PIEDADE, M. T. F.; JUNK. W. J. Classificação e delineamento das áreas úmidas brasileiras e de seus macrohabitats. Cuiabá: EdUFMT, 2015.

ESQUERDO, J. C. D. M.; ANTUNES, J. F. G. Monitoramento temporal de variáveis espectrais em áreas do Pantanal utilizando dados AVHRR/NOAA-17. Revista Brasileira de Cartografia, Rio de Janeiro, n. 62, p. 639-647, 2010. Disponível em:

https://ainfo.cnptia.embrapa.br/digital/bitstream/item/17302/1/p45.pdf. Acesso em: 14 out. 2019.

FERRARI, D. L.; SILVA, J. S. V.; ABDON, M. M. Avaliação do uso de NDVI em imagens CBERS-2B/CCD na caracterização de pastagens degradadas no município de Camapuã, MS. In: SIMPÓSIO DE GEOTECNOLOGIAS NO PANTANAL, 2., 2009, Corumbá. Anais [...]. Corumbá: INPE, 2009. p. 402-411.

FERREIRA, L. G.; HUETE, A. R. Assessing the seasonal dynamics of the Brazilian Cerrado vegetation through the use of spectral vegetation indices. International Journal of Remote Sensing, London, v. 25, n. 10, p. 1837-1860, 2004. Disponível em:

https://www.tandfonline.com/doi/abs/10.1080/0143116031000101530?journalCode=tres20. Acesso em: 14 out. 2019.

GOLTZ, E.; BRANDÃO, D.; TOMÁS, L. R.; MANTELLI, L. R.; ADAMI, M.; SHIMABUKURO, Y. E.; FORMAGGIO, A. R. Utilização de índices espectrais de vegetação do sensor MODIS na determinação de áreas suscetíveis a alagamento no Pantanal Sul Matogrossense.

Revista Brasileira de Cartografia, Rio de Janeiro, n. 59, p. 87-95, 2007. Disponível em: http://mtc-m16b.sid.inpe.br/col/sid.inpe.br/mtc-m17@80/2006/12.08.13.28/doc/p80.pdf. Acesso em: 14 out. 2019.

GU, Y.; HUNT, E.; WARDLOW, B.; BASARA, J. B.; BROWN, J. F.; VERDIN, J. P. Evaluation of MODIS NDVI and NDWI for vegetation drought monitoring using Oklahoma Mesonet soil moisture data. Geophysical Research Letters, Hoboken, v. 35, n. 22, p. 1-5, 2008.

Disponível em: https://agupubs.onlinelibrary.wiley.com/doi/full/10.1029/2008GL035772. Acesso em: 14 out. 2019.

IBGE. Manual técnico da vegetação brasileira. Rio de Janeiro: IBGE, 2012.

IMMERZEEL, W. W.; QUIROZ, R. A.; JONG, S. M. Understanding precipitation patterns and land use interaction in Tibet using harmonic analysis of SPOT VGT-S10 NDVI time series.

International Journal of Remote Sensing, London, v. 26, n. 11, p. 2281-2296, 2005.

Disponível em: https://www.tandfonline.com/doi/full/10.1080/01431160512331326611.

Acesso em: 14 out. 2019.

JUNK, W. J.; SILVA, C. J.; CUNHA, C. N. The Pantanal: ecology, biodiversity and sustainable management of a large neotropical seasonal wetland. Bulgaria: Pensoft Publishers, 2011.

KMITTA, I. R. Experiências vividas, naturezas construídas: enchentes no Pantanal (Porto Murtinho - 1970-1990). 2010. Dissertação (Mestrado em História) - Faculdade de Ciências Humanas, Universidade Federal da Grande Dourados, Dourados, 2010.

MACALISTER, C.; MAHAXAY, M. Mapping wetlands in the Lower Mekong Basin for wetland resource and conservation management using Landsat ETM images and field survey data.

Journal of Environmental Management, London, v. 90, n. 7, p. 2130-2137, 2009.

Disponível em: https://www.ncbi.nlm.nih.gov/pubmed/18467019. Acesso em: 14 out. 2019.

MACHADO, T. S.; CAIONI, C.; FERNANDES, R. S.; NEVES, R. J.; NEVES, S. M. A. S. Análise de NDVI e NDWI em diferentes intensidades pluviométricas para bacia hidrográfica do rio do Cachoeirinha, Mato Grosso, Brasil. In: SIMPÓSIO DE GEOTECNOLOGIAS NO PANTANAL, 5., 2014, Campo Grande. Anais [...]. Campo Grande: Embrapa Informática Agropecuária, 2014. p. 690-699. 
MIOTO, C. L.; PARANHOS FILHO, A. C.; ALBREZ, E. A. Contribuição à caracterização das sub-regiões do Pantanal. Entre-Lugar, Dourados, v. 3, n. 6, p. 165-180, 2012. Disponível em: http://ojs.ufgd.edu.br/index.php/entre-lugar/article/view/2453/1404. Acesso em: 14 out. 2019.

MIURA, T.; HUETE, A. R.; YOSHIOKA, H.; HOLBEN, B. N. An error and sensitivity analysis of atmospheric resistant vegetation indices derived from dark target-based atmospheric correction. Remote Sensing of Environment, New York, v. 78, p. 284-298, 2001. Disponível em: https://www.sciencedirect.com/science/article/abs/pii/S0034425701002231. Acesso em: 14 out. 2019.

MORAES, E. C.; PEREIRA, G.; ARAI, E. Uso dos produtos EVI do sensor MODIS para a estimativa de áreas de alta variabilidade intra e interanual no bioma Pantanal. Geografia, Rio Claro, v. 34, n. esp., p. 757-767, 2009. Disponível em: https://www.geopantanal.cnptia.embrapa.br/publicacoes/2geo/Cap-11.pdf. Acesso em: 14 out. 2019.

PADOVANI, C. R. Dinâmica espaço-temporal das inundações do Pantanal. 2010. Tese (Doutorado em Ecologia Aplicada) - Centro de Energia Nuclear na Agricultura, Escola Superior de Agricultura "Luiz de Queiroz", Piracicaba, 2010.

PADOVANI, C. R.; CAMOLESI JÚNIOR, L.; BONAFE, P.; VETTORAZZI, C. A.; DIAS, R. A. P.; DIAS, C. T. Sistema de monitoramento e alerta de inundações e secas no Pantanal. In: SIMPÓSIO BRASILEIRO DE SENSORIAMENTO REMOTO, 15., 2011, Curitiba. Anais [...]. Curitiba: INPE, 2011. p. 5140.

PENATTI, N. C. Geobotânica e fenologia da superfície terrestre no estudo da diversidade do Pantanal: uma abordagem multi-sensor. 2014. Tese (Doutorado em Geociências) - Instituto de Geociências, Universidade de São Paulo, São Paulo, 2014.

PORTZ, L.; GUASSELLI, L.; CORRÊA, I. Variação espacial e temporal de NDVI na Lagoa do Peixe, RS. Revista Brasileira de Geografia Física, Recife, v. 4, n. 5, p. 897-908, 2011. Disponível em: https://periodicos.ufpe.br/revistas/rbgfe/article/view/232706/26713. Acesso em: 14 out. 2019.

QUIROZ, R.; YARLEQUÉ, C.; POSADAS, A.; MARES, V.; IMMERZEEL, W. W. Improving daily rainfall estimation from NDVI using a wavelet transform. Environmental Modelling \& Software, Oxford, v. 26, n. 2, p. 201-209, 2011. Disponível em:

https://www.sciencedirect.com/science/article/pii/S1364815210002100. Acesso em: 14 out. 2019.

SCHOWENGERDT, R. A. Remote sensing: models and methods for image processing. Amsterdam: Elsevier, 2006.

SILVA, C. J.; WANTZEN, K. M.; CUNHA, C. N.; MACHADO, F. A. Biodiversity in the Pantanal wetland, Brasil. In: GOPAL, B.; JUNK, W. J.; DAVIS, J. A. (ed.). Biodiversity in wetlands: assessment, function and conservation. Leiden: Backhuys Publishers, 2001. v. 2, p. 187-215. Disponível em:

https://www.researchgate.net/publication/27281375_Biodiversity_in_wetlands_assessment_f unction_and_conservation_Vol_1. Acesso em: 14 out. 2019.

SILVA, M. H. S. O Pantanal sul mato-grossense um meio ambiente territorializado. Fórum Ambiental da Alta Paulista, São Paulo, v. 9, n. 7, p. 149-166, 2013. Disponível em:

http://amigosdanatureza.org.br/publicacoes/index.php/forum_ambiental/article/view/553/578. Acesso em: 21 out. 2019.

SILVEIRA, S. W. G. Análise de desempenho de produtos MODIS para modelagem da dinâmica de inundação do Pantanal Mato-Grossense. 2015. Tese (Doutorado em Física Ambiental) - Instituto de Física, Universidade Federal de Mato Grosso, Cuiabá, 2015. 
VIANA, D. R.; ALVALÁ, R. C. S. Avaliação de desempenho de índices de vegetação na caracterização de classes de cobertura da terra na região do Pantanal nas estações seca e chuvosa. In: SIMPÓSIO DE GEOTECNOLOGIAS NO PANTANAL, 3., 2010, Cáceres. Anais [...]. Cáceres: Embrapa Informática Agropecuária, 2010. p. 434-446.

WANG, J.; RICH, P. M.; PRICE, K. P. Temporal responses of NDVI to precipitation and temperature in the central Great Plains, USA. International Journal of Remote Sensing, London, v. 24, p. 2345-2364, 2003. Disponível em:

https://www.tandfonline.com/doi/abs/10.1080/01431160210154812. Acesso em: 14 out. 2019.

\section{AGRADECIMENTOS}

À Coordenação de Aperfeiçoamento de Pessoal de Nível Superior (CAPES), pela concessão da bolsa de estudo do Mestrado do G.B.M. Alves e à Fundação de Amparo à Pesquisa de Mato Grosso (FAPEMAT).

Recebido: julho de 2019. Aceito: outubro de 2019. 